\title{
Effect of high-volume hemofiltration on children with sepsis
}

\author{
Botao Ning ${ }^{1 \#}$, Sheng Ye ${ }^{2 \#}$, Yi Lyu ${ }^{3 \#}$, Fan Yin ${ }^{1}$, Zhenjie Chen ${ }^{2 \#}$ \\ ${ }^{1}$ Pediatric Intensive Care Unit, Shanghai Children's Medical Center Affiliated to Shanghai Jiao Tong University School of Medicine, Shanghai \\ 200127, China; '2Pediatric Intensive Care Unit, the Children's Hospital of Zhejiang University, School of Medicine, Shanghai 310052, China; \\ ${ }^{3}$ Department of Anesthesiology, Minhang Hospital, Fudan University, Shanghai 200032, China \\ Contributions: (I) Conception and design: B Ning; (II) Administrative support: S Ye; (III) Provision of study materials or patients: S Ye, Z Chen; (IV) \\ Collection and assembly of data: Z Chen; (V) Data analysis and interpretation: Y Lyu, F Yin, Z Chen; (VI) Manuscript writing: All authors; (VII) \\ Final approval of manuscript: All authors. \\ \#These authors contributed equally to this work. \\ Correspondence to: Prof. Botao Ning. Pediatric Intensive Care Unit, Shanghai Children's Medical Center Affiliated to Shanghai Jiao Tong University \\ School of Medicine, Shanghai 200127, China. Email: ningbotao1977@126.com.
}

\begin{abstract}
Background: Sepsis has always been a challenge in pediatric intensive care unit (PICU) with poor prognosis. In order to evaluate the effect between routine continuous renal replacement therapy (CRRT) and high-volume hemofiltration (HVHF) in children with sepsis, we performed out this prospective, randomized, controlled, open-label trial.
\end{abstract}

Methods: Forty-seven children with sepsis were enrolled from January 2015 to December 2016. Twentytwo patients in Control group received routine CRRT and 25 patients in HVHF group received HVHF within 6 hours after the diagnosis of sepsis. The oxygenation index, serum creatinine, urea, lactate, inflammatory cytokines (IL-6, IL-10, and TNF- $\alpha$ ), pediatric risk of mortality III (PRISM III) and 28-day mortality rate were collected and compared.

Results: The oxygenation index in HVHF group and Control group was significantly increased at 48 hours $(\mathrm{P}<0.01)$ and 72 hours after treatment $(\mathrm{P}<0.05)$. The same result of arterial lactate was observed. Serum creatinine, urea, IL-6, IL-10, TNF- $\alpha$ and PRISM III score were significantly ameliorated after 72 hours treatment in HVHF group $(\mathrm{P}<0.01)$, while there was no significant difference in Control group. After 72 hours of treatment, the oxygenation index, lactate, serum creatinine, urea, TNF- $\alpha$, IL-6, IL-10 and PRISM III score in HVHF group were significantly improved compared with Control group $(\mathrm{P}<0.01)$. There is no significant difference on 28-day mortality between the two groups $(\mathrm{P}>0.05)$.

Conclusions: HVHF might be an effective treatment for children with sepsis.

Keywords: Children; sepsis; high-volume hemofiltration; efficacy

Submitted Dec 16, 2019. Accepted for publication Mar 18, 2020.

doi: $10.21037 /$ tp.2020.03.13

View this article at: http://dx.doi.org/10.21037/tp.2020.03.13

\section{Introduction}

Sepsis is a life-threatening organ dysfunction due to a dysregulated host response to infection (1), which caused 5.3 million deaths each year. The mortality of sepsis is up to $30-50 \%$ (2). sepsis remains the leading cause of death in the intensive care unit (ICU). The imbalance of immune response plays an important role in the pathophysiology of sepsis, and may cause organ dysfunction in sepsis (3).
The early pro-inflammatory stage of sepsis is a defensive response of the body to invading microorganisms. This is characterized by release of pro-inflammatory mediators [tumor necrosis factor (TNF), interleukin (IL)-1, IL6, IL-8, platelet chemokines, and myocardial depressant factor]. However, excessive release of pro-inflammatory mediators can result in damage to the host. Also, excessive anti-inflammatory response impairs immunity and increases the number of immune-regulatory cells, leading 
to immunosuppression. As the two poles of the immune response process, inflammation and anti-inflammatory reactions run through the entire process of sepsis development, and together determine the direction of the disease $(4,5)$.

Continuous renal replacement therapy (CRRT) is a major treatment modality for patients with sepsis. In addition to advantages in correcting water and electrolyte disorders, maintaining hemodynamic stability and promoting renal function recovery, studies have proposed a role in immunomodulation by efficiently removing proinflammatory and anti-inflammatory cytokines through CRRT $(6,7)$. High volume hemofiltration (HVHF) is a mode of CRRT with higher volume which are expected to achieve higher removal efficiency of cytokines. Based on this, several clinical trials have been performed to investigating the clearance efficiency of cytokines by HVHF in patients with sepsis. However, the effect of HVHF on cytokines clearance, its clinical efficacy and effect on children are not yet clear (8-11). By conducting a prospective cohort study, we aimed to investigate the treatment effect of HVHF in children with sepsis in this study.

\section{Methods}

\section{Study setting}

We conducted this prospective, randomized, controlled, open-label trial that investigate effect of high-volume hemofiltration on children with sepsis in the pediatric intensive care unit (PICU) of Children's Hospital of Zhejiang University School of Medicine. The study was conducted from January 2015 to December 2016. The study was approved by the Ethics Committee of the Children's Hospital of Zhejiang University School of Medicine. Informed written consents were obtained from the parents of the patients.

\section{Study population}

Participants were eligible for enrollment if they meet the following criteria: (I) diagnosed as sepsis, (II) less than 6 hours to establish a diagnosis of sepsis, and (III) aged less than 18 years old. The sepsis meets the diagnostic criteria in the Society of Critical Care Medicine/European Society of Intensive Care Medicine/American College of Chest
Physicians/American Thoracic Society/Surgical Infection Society (SCCM/ESICM/ACCP/ATS/SIS) (12) or the Third International Consensus Definitions for Sepsis and Septic Shock (1). Patients who have received relevant blood purification treatment before admission, children with genetic metabolic disease, HIV infection or other immune deficiency will be excluded. Patients were randomized to receive standard treatment plus routine CRRT (Control group) and standard treatment plus HVHF (HVHF group). We use randomized block design for grouping: out of every four patients, two were allocated to Control group, and two to HVHF group at random. Physicians and nurses were not blinded to the allocated treatment.

\section{Treatment assignments}

All patients received standard treatment including routine fluid resuscitation, administration of antibiotics, application of vasoactive and inotropic agents, balance of fluid, blood gas and electrolyte, etc. (3). All patients were treated with the Prismaflex system (Gambro, Sweden). The AN69 membrane (sulfonated polyacrylonitrile membrane) was used in this study, on which the sulfo had a large quantity of negative charge, which had a strong removal effect for various medium-sized molecules and macromolecules. CRRT treatment started within 6 hours after the diagnosis of sepsis. The continuous veno-venous hemofiltration (CVVH) model was adopted. The ratio of pre-dilution $v s$. post-dilution was $1: 2$. The rates of replacement fluid were 30 and $60 \mathrm{~mL} / \mathrm{kg} / \mathrm{h}$ replacement fluid for CRRT and HVHF, respectively. Blood pump flow was $3 \mathrm{~mL} / \mathrm{kg} / \mathrm{min}$ and the ultrafiltration volume was set to "no ultrafiltration when patients had normal renal function" and to an "ultrafiltration rate at $1-2 \mathrm{~mL} / \mathrm{kg} / \mathrm{h}$ when patients had oliguria or anuria". For anticoagulation, a conventional continuous intravenous infusion of heparin was prescribed to maintain the level of activated partial thromboplastin time (APTT) at 1.5-2 times the control value. The replacement fluid constituted of $1,500 \mathrm{~mL}$ normal saline,

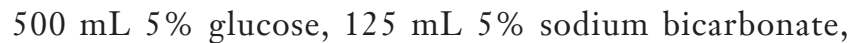
$10 \mathrm{~mL} 10 \%$ calcium gluconate, $6 \mathrm{~mL} 10 \%$ potassium chloride and $0.75 \mathrm{~mL} 25 \%$ magnesium sulfate.

\section{End points}

The primary end point was death from any cause within 28 days after randomization. Secondary end points included 
Table 1 Demographic characteristics of patients

\begin{tabular}{lccc}
\hline Variables & $\begin{array}{c}\text { Control group A } \\
(\mathrm{n}=22)\end{array}$ & $\begin{array}{c}\text { HVHF group B } \\
(\mathrm{n}=25)\end{array}$ & P value \\
\hline Male sex & $12(54.5 \%)$ & $14(56 \%)$ & $>0.05$ \\
Ager (years) & $2.6 \pm 2.0$ & $3.1 \pm 2.2$ & $>0.05$ \\
Weight (kg) & $13.5 \pm 11.0$ & $16.3 \pm 15.3$ & $>0.05$ \\
Source of & & & $\mathrm{N} / \mathrm{A}$ \\
infection & 15 & 13 & \\
Pneumonia & 2 & 4 & \\
Encephalitis & 3 & 2 & \\
Enteritis & 1 & 2 & \\
Kidney & & & \\
disease & 1 & 1 & \\
Cellulitis & 0 & 1 & \\
Peritonitis & 0 & & \\
Endocarditis & & & \\
\hline
\end{tabular}

cytokines (IL-6, IL-10, TNF- $\alpha$ ) levels after treatment, the oxygenation index, lactate, serum creatinine, urea and PRISM III score. Complications in the trail process were assessed additionally.

\section{Data collection and measurement}

Prior to treatment and at 24,48 , and 72 hours after treatment, we recorded the oxygenation index, arterial blood lactate concentrations, serum creatinine and blood urea concentrations, and serum inflammatory cytokine concentrations (IL-6, IL-10, and TNF- $\alpha$ ). The mortality rates of the two groups and the PRISM III scores of pretreatment and post-treatment were also recorded. The CBA Human Th1/Th2 Cytokine Kit II (BD Biosciences; San Jose, CA, USA) was used to determine serum TNF- $\alpha$, IL-2, IL-4, IL-6, IL-10, and IFN- $\gamma$ levels following the manufacturer protocol through flow cytometry (FCM).

\section{Statistical analysis}

SPSS software, version 17.0 (SPSS Institute Inc), was used for statistical analysis. All data are tested for normality and expressed as mean \pm standard deviation. A $t$-test was used for continuous variables, and $\chi^{2}$ test was used for categorical variables. Analyses of data were made by an independent statistician. $\mathrm{P}<0.05$ indicated a significant difference.

\section{Results}

\section{General characteristics of the children}

Among the 47 patients, 26 were boys and 21 were girls. Their age ranged from 2 months to 13 years, with a mean age of $3.0 \pm 2.7$ years. Their weight ranged from $4.3-51 \mathrm{~kg}$, with a mean weight of $15.1 \pm 12.4 \mathrm{~kg}$. There were 12 boys

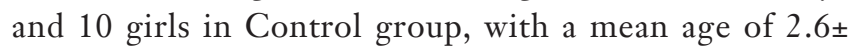
2.0 years and mean weight of $13.5 \pm 11.0 \mathrm{~kg}$. There were 14 boys and 11 girls in HVHF group, with a mean age of $3.1 \pm 2.2$ years and mean weight of $16.3 \pm 15.3 \mathrm{~kg}$. The ages and weights between the two groups of children were not significantly different. The underlying diseases of the two groups of children are shown in Table 1 .

\section{Primary outcome}

Among the 25 patients in HVHF group, 5 died and 20 left PICU and survived to 28 days. Among the 22 patients in Control group, 9 died and 13 were left PICU and survived to 28 days. There was no significant difference in 28-day mortality between the Control group and HVHF group $\left(\chi^{2}=2.446, \mathrm{P}=0.201\right)$.

\section{Secondary outcomes}

\section{Comparison of the oxygenation index in children}

The mean values of arterial oxygenation indices of children in HVHF group at 0, 24, 48 and 72 hours were $258.5 \pm 114.3,294.9 \pm 108.4,346.9 \pm 119.1$, and $406.9 \pm$ $103.0 \mathrm{mmHg}$, respectively. Their oxygenation indexes at 48 and 72 hours were significantly higher compared with 0 hour $(\mathrm{P}<0.01)$. The arterial oxygenation indices of children in Control group at 0, 24, 48 and 72 hours were $232.0 \pm 130.6,260.5 \pm 130.6,277.2 \pm 112.5$, and $316.7 \pm 142.2 \mathrm{mmHg}$, respectively, it significantly increased $(\mathrm{P}<0.05)$ until 72 hours after treatment. After 72 hours of treatment, the arterial oxygenation index in HVHF group was significantly higher than that in Control group $(\mathrm{P}<0.05$, Table 2).

\section{Comparison of arterial blood lactate concentrations in children}

The mean value of arterial blood lactate concentrations 


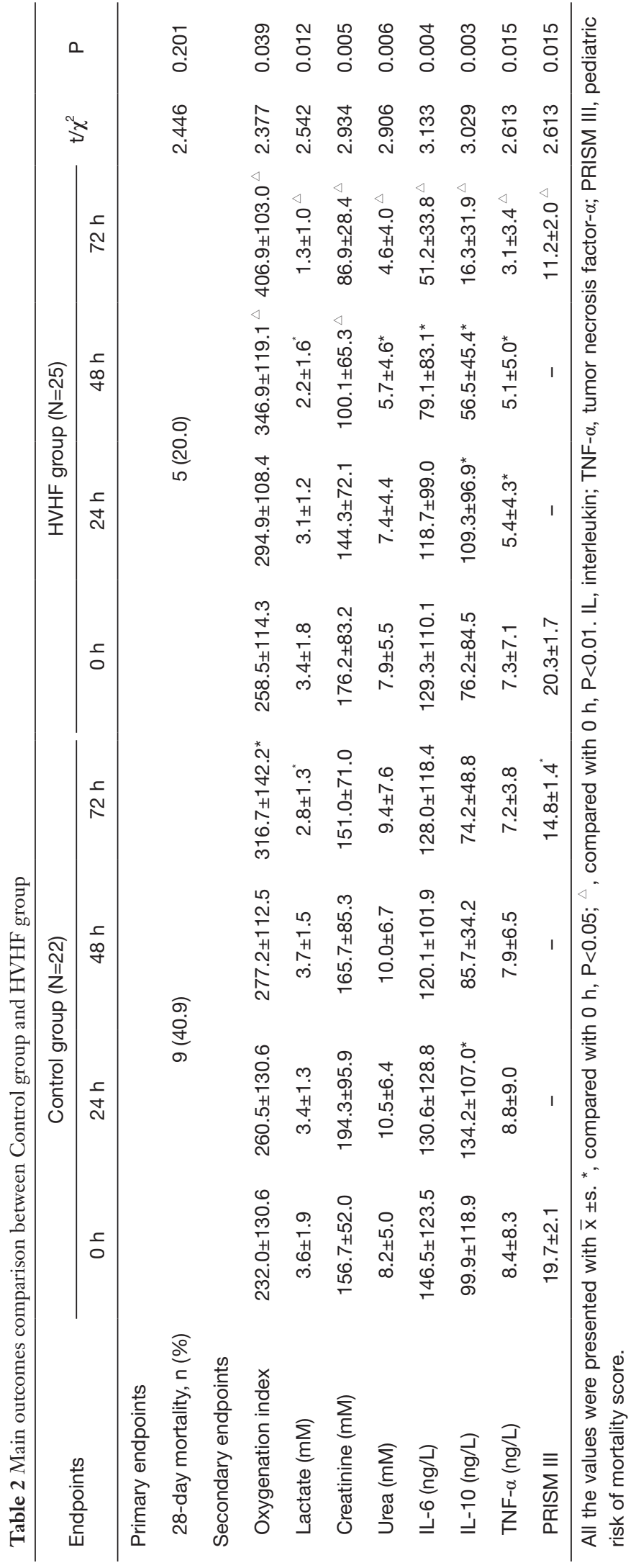

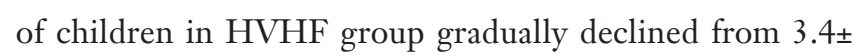
$1.8 \mathrm{mmol} / \mathrm{L}$ pre-treatment to $3.1 \pm 1.2 \mathrm{mmol} / \mathrm{L}$ at 24 hours, $2.2 \pm 1.6 \mathrm{mmol} / \mathrm{L}$ at 48 hours $(\mathrm{P}<0.05)$, and $1.3 \pm 1.0 \mathrm{mmol} / \mathrm{L}$ at 72 hours $(\mathrm{P}<0.01)$. In Control group, it was 3.6 \pm 1.9 , $3.4 \pm 1.3,3.7 \pm 1.5$, and $2.8 \pm 1.3 \mathrm{mmol} / \mathrm{L}(\mathrm{P}<0.05)$ at 0,24 , 48 , and 72 hours, respectively. After 72 hours of treatment, arterial blood lactate concentrations of children in HVHF group were lower than those in children in Control group $(\mathrm{P}<0.01$, Table 2).

\section{Comparison of serum creatinine concentrations in children}

The mean value of serum creatinine concentrations of children in HVHF group decreased from 176.2 \pm $83.2 \mu \mathrm{mol} / \mathrm{L}$ at 0 hour to $144.3 \pm 72.1 \mu \mathrm{mol} / \mathrm{L}$ at 24 hours, $100.1 \pm 65.3 \mu \mathrm{mol} / \mathrm{L}$ at 48 hours $(\mathrm{P}<0.01)$, and $86.9 \pm$ $28.4 \mu \mathrm{mol} / \mathrm{L}$ at 72 hours $(\mathrm{P}<0.01)$. In Control group, it was $156.7 \pm 52.0,194.3 \pm 95.9,165.7 \pm 85.3$, and $151.0 \pm$ $71.0 \mu \mathrm{mol} / \mathrm{L}$ at $0,24,48$, and 72 hours, respectively, with no significant difference between pre-treatment and posttreatment data $(\mathrm{P}>0.05)$. After 72 hours of treatment, serum creatinine concentrations of children in HVHF group were significantly lower than those of children in Control group $(\mathrm{P}<0.01$, Table 2).

\section{Comparison of blood urea concentrations in children}

The mean value of blood urea concentrations of children in HVHF group gradually decreased from $7.9 \pm 5.5 \mathrm{mmol} / \mathrm{L}$ pre-treatment to $7.4 \pm 4.4 \mathrm{mmol} / \mathrm{L}$ at 24 hours $(\mathrm{P}>0.05)$, $5.7 \pm 4.6 \mathrm{mmol} / \mathrm{L}$ at 48 hours $(\mathrm{P}<0.05)$, and $4.6 \pm$ $4.0 \mathrm{mmol} / \mathrm{Lat} 72$ hours $(\mathrm{P}<0.01)$ after treatment. Blood urea concentrations of children in Control group were 8.2 \pm 5.0 , $10.5 \pm 6.4,10.0 \pm 6.7$, and $9.4 \pm 7.6 \mathrm{mmol} / \mathrm{L}$ at $0,24,48$, and 72 hours after treatment, respectively, with no significant difference between pre-treatment and post-treatment data $(\mathrm{P}>0.05)$. After 72 hours of treatment, blood urea concentrations in HVHF group were significantly lower than those in Control group $(\mathrm{P}<0.01$, Table 2).

\section{Changes in serum cytokine concentrations in children} The mean value of serum IL- 6 concentrations of children in HVHF group gradually declined from $129.3 \pm 110.8 \mathrm{ng} / \mathrm{L}$ pre-treatment to $118.7 \pm 99.0 \mathrm{ng} / \mathrm{L}$ at 24 hours, $79.1 \pm$ $83.1 \mathrm{ng} / \mathrm{L}$ at 48 hours $(\mathrm{P}<0.05)$, and $51.2 \pm 33.8 \mathrm{ng} / \mathrm{L}$ at 72 hours $(\mathrm{P}<0.01)$ after treatment. Serum IL-6 concentrations of children in Control group were $146.5 \pm 123.3,130.6 \pm 128.8,120.1 \pm 101.9$, and $128.0 \pm$ $118.4 \mathrm{ng} / \mathrm{L}$ at $0,24,48$, and 72 hours after treatment, 
respectively, with no significant difference between pre- and post-treatment data. After 72 hours of treatment, serum IL-6 concentrations in HVHF group were significantly lower than those in Control group $(\mathrm{P}<0.01$, Table 2).

Serum IL-10 concentrations of children in HVHF group declined from $76.2 \pm 84.5 \mathrm{ng} / \mathrm{L}$ pre-treatment to $109.3 \pm 96.9 \mathrm{ng} / \mathrm{L}$ at 24 hours $(\mathrm{P}<0.05), 56.5 \pm 45.4 \mathrm{ng} / \mathrm{L}$ at 48 hours $(\mathrm{P}<0.05)$, and $16.3 \pm 31.9 \mathrm{ng} / \mathrm{L}$ at 72 hours $(\mathrm{P}<0.05)$ after treatment. Serum IL-10 concentrations of children in Control group increased from $99.9 \pm 118.9 \mathrm{ng} / \mathrm{L}$ pre-treatment to $134.2 \pm 107.0 \mathrm{ng} / \mathrm{L}$ at 24 hours $(\mathrm{P}<0.05)$, with no differences at 48 hours $(85.7 \pm 34.2 \mathrm{ng} / \mathrm{L})$ and at 72 hours after treatment $(74.2 \pm 48.8 \mathrm{ng} / \mathrm{L})$. After 72 hours of treatment, serum IL-10 concentrations in HVHF group were significantly lower than that in Control group compared with pre-treatment (Table 2).

Serum TNF- $\alpha$ concentrations of children in HVHF group gradually decreased from $7.3 \pm 7.1 \mathrm{ng} / \mathrm{L}$ pre-treatment to $5.4 \pm 4.3 \mathrm{ng} / \mathrm{L}$ at 24 hours $(\mathrm{P}<0.05), 5.1 \pm 5.0 \mathrm{ng} / \mathrm{L}$ at 48 hours $(\mathrm{P}<0.05)$, and $3.1 \pm 3.4 \mathrm{ng} / \mathrm{L}$ at 72 hours $(\mathrm{P}<0.01)$ after treatment. Serum TNF- $\alpha$ concentrations of children in Control group were $8.4 \pm 8.3,8.8 \pm 9.0,7.9 \pm 6.5$, and $7.2 \pm$ $3.8 \mathrm{ng} / \mathrm{L}$ at 24,48 , and 72 after treatment, respectively, with no significant difference between pre-treatment and posttreatment data $(\mathrm{P}>0.05)$. After 72 hours of treatment, serum TNF- $\alpha$ concentrations in HVHF group were significantly lower than those in Control group $(\mathrm{P}<0.05$, Table 2).

\section{Changes in the PRISM III score during treatment}

The mean value of PRISM III score in Control group and HVHF group before treatment was significantly lower than that after 72 hours of treatment $(19.7 \pm 2.1 \mathrm{vs}$. $14.8 \pm 1.4, \mathrm{P}<0.05 ; 20.3 \pm 1.7$ vs. $11.2 \pm 2.0, \mathrm{P}<0.01)$. After 72 hours of treatment, the PRISM III score in HVHF group was significantly lower than that in Control group $(\mathrm{P}<0.05$, Table 2).

\section{Complications}

During HVHF therapy, 7 patients among HVHF group $(7 / 30,23.33 \%)$ showed low potassium levels and hypocalcemia in CRRT. These patients returned to normal after corresponding electrolytes were added to the displacement liquid. Four patients among HVHF group $(4 / 30,13.33 \%)$ showed hypotension during their treatment, which was considered to be related to the excessive removal of fluid after ruling out other potential causes. These patients returned to normal after fluid therapy and adjustment of fluid removal. No severe hemolysis, thrombosis, hemorrhage or unstable blood pressure was observed in any of the patients.

\section{Discussion}

Sepsis has always been a challenge in critical care medicine. The main pathophysiology of sever sepsis is a "waterfalllike" release of plenty of inflammatory mediators, resulting in SIRS and multiple organ dysfunction syndrome (MODS). Under normal circumstances, pro-inflammatory and anti-inflammatory responses in the body are in a state of dynamic equilibrium. Overreaction of either side can cause nonequilibrium, resulting in either immune enhancement (e.g., SIRS) or immunosuppression (e.g., compensatory anti-inflammatory response syndrome). CRRT has benefits of accurate fluid management and capability of removing inflammatory mediators, and it is applied to treat sepsis and achieves a certain efficacy (13-15). Cole et al. (9) reported that continuous blood purification therapy volume could be classified as conventional and high volume of hemofiltration, which determine the type of filtration media and play an important role in sepsis and MODS. There is not yet a consensus on the therapeutic volume for HVHF, especially for children continuous hemofiltration with a replacement fluid rate of $>50 \mathrm{~mL} / \mathrm{kg} / \mathrm{h}$ is generally accepted as HVHF.

In our study, HVHF with a replacement fluid volume of $60 \mathrm{~mL} / \mathrm{kg} / \mathrm{h}$ was used for treatment of sepsis. Mortality rate at day 28 was used as the primary endpoint to assess prognosis of sepsis patients. The mortality rate at day 28 in HVHF group was lower than that in Control group, but there was no significantly statistical difference. Ronco et al. (16) found that the survival rate of septic shock patients increased from $18 \%$ to $47 \%$ as the replacement fluid volume raised from 35 to $45 \mathrm{~mL} / \mathrm{kg} / \mathrm{h}$. However, Parikh et al. failed to confirm that high-volume hemofiltration $(40 \mathrm{~mL} / \mathrm{kg} / \mathrm{h})$ could improve patients survival rate at day 90 compared to low-volume hemofiltration $(20 \mathrm{~mL} / \mathrm{kg} / \mathrm{h})(17)$. Due to the age distribution and the severity of the disease, clinical studies on high-flow hemofiltration for sepsis have shown different results, suggesting a possibility of highvolume hemofiltration benefit in selected populations (18).

The possibilities of increasing the clearance of soluble cytokines through high intensity hemofiltration have been proposed previously $(19,20)$. In this study, circulating TNF- $\alpha$, IL-6, IL-10 levels from HVHF group showed a significant decrease compared with those from Control group after 72 hours of treatment. Besides, compared with 
the Control group, the cytokine levels of HVHF group experienced faster cytokine decline. This may indicate that circulating cytokines were more efficiently removed when CRRT was applied at a volume higher than that administered under standard care. The serum cytokine levels evaluated in this study were somewhat lower compared with recent reports containing cytokine levels in sepsis patients. We believe that differences in detection methods and patient conditions are the source of this difference.

Our study showed that for children in HVHF group, serum creatinine and blood urea concentrations showed a gradual declining trend, with a decrease at 72 hours after treatment compared with 0 hour $(\mathrm{P}<0.01)$. However, there were no significant differences in serum creatinine and blood urea concentrations in Control and HVHF group before and after treatment. For children with sepsis, early HVHF is able to not only reduce the fluid overload caused upon fluid resuscitation, but can also remove metabolites, such as creatinine and urea, quickly and effectively. A retrospective study of 113 critically ill children showed that, before CVVH, children with a relatively light fluid overload have a higher survival rate, especially for those with MODS (21). HVHF can both remove excess fluid and balance metabolic derangements, which might be one of the reasons for the higher survival rate of HVHF group, but there is no significantly statistical difference.

In sepsis, increased serum lactate concentrations reflect tissue hypoperfusion and inadequate oxygen supply, which predicts the prognosis of the disease. Increased lactate concentrations are the key to MODS death. The higher the lactate concentration, the more severe the disease was (22). When sepsis is complicated by refractory shock and MODS, the extent and duration of increased lactate concentrations are associated with mortality. Mikkelsen et al. (23) measured blood lactate concentrations in 830 patients with sepsis, and assigned them into the groups of mildly increased $(<2.0 \mathrm{mmol} / \mathrm{L})$, moderately increased $(2.0-3.9 \mathrm{mmol} / \mathrm{L})$, and severely increased $(>4.0 \mathrm{mmol} / \mathrm{L})$ lactate concentrations. They found that regardless of whether patients suffered from shock, 28-day mortality in the group of patients with severely increased lactate was significantly higher than the other two groups. This finding indicated that the level of lactate at the early stage of sepsis can be used as an indicator for evaluation of prognosis for sepsis. In our study, lactate concentrations in children in HVHF group were significantly decreased at 48 hours, and returned to normal concentrations at 72 hours, while lactate concentrations in Control group were significantly decreased at 72 hours compared with those before treatment. These findings suggested that HVHF accelerated blood lactate clearance, and this ameliorate blood $\mathrm{pH}$ due to reduction of lactate, thus improved the in-vivo microcirculation and the efficiency of vasoactive agents in ill children.

On the basis of conventional treatment of sepsis, HVHF treatment can effectively remove inflammatory mediators, reduce excessive inflammation in patients with sepsis, improve metabolism of tissues, and stabilize in-vivo microcirculation. This process improves the condition of sepsis and improves the prognosis. HVHF may be an effective treatment for sepsis. Furthermore, the results of the presented study are preliminary data and further studies should be stated.

\section{Acknowledgments}

Funding: The Project was Support by the Shanghai Natural Science Foundation of China (No. 19ZR1432900), the National Natural Science Foundation of China (no. 81270045) and Zhejiang Provincial Natural Science Foundation of China (No: LY16H160024).

\section{Footnote}

Conflicts of Interest: All authors have completed the ICMJE uniform disclosure form (available at http://dx.doi. org/10.21037/tp.2020.03.13). The authors have no conflicts of interest to declare.

Ethical Statement: The authors are accountable for all aspects of the work in ensuring that questions related to the accuracy or integrity of any part of the work are appropriately investigated and resolved. The study was approved by the Ethics Committee of the Children's Hospital of Zhejiang University School of Medicine. Informed written consents were obtained from the parents of the patients.

Open Access Statement: This is an Open Access article distributed in accordance with the Creative Commons Attribution-NonCommercial-NoDerivs 4.0 International License (CC BY-NC-ND 4.0), which permits the noncommercial replication and distribution of the article with the strict proviso that no changes or edits are made and the original work is properly cited (including links to both the 
formal publication through the relevant DOI and the license). See: https://creativecommons.org/licenses/by-nc-nd/4.0/.

\section{References}

1. Seymour CW, Liu VX, Iwashyna TJ, et al. [3.0] Assessment of Clinical Criteria for Sepsis: For the Third International Consensus Definitions for Sepsis and Septic Shock (Sepsis-3). JAMA 2016;315:762-74.

2. Palencia Herrejón E, Bueno Garcia B. New clinical practice guidelines of the surviving sepsis campaign: a critical appraisal. Med Intensiva 2013;37:600-4.

3. Hotchkiss RS, Moldawer LL, Opal SM, et al. Sepsis and septic shock. Nat Rev Dis Primers 2016;2:16045.

4. Delano MJ, Ward PA. The immune system's role in sepsis progression, resolution, and long-term outcome. Immunol Rev 2016;274:330-53.

5. Hotchkiss RS, Sherwood ER. Immunology. Getting sepsis therapy right. Science 2015;347:1201-2.

6. Morgera S, Slowinski T, Melzer C, et al. Renal replacement therapy with high-cutoff hemofilters: Impact of convection and diffusion on cytokine clearances and protein status. Am J Kidney Dis 2004;43:444-53.

7. Sanchez-Izquierdo JA, Vela JLP, Quintana MJL, et al. Cytokines clearance during venovenous hemofiltration in the trauma patient. American Journal of Kidney Diseases 1997;30:483-8.

8. Ghani RA, Zainudin S, Ctkong N, et al. Serum IL-6 and IL-1-ra with sequential organ failure assessment scores in septic patients receiving high-volume haemofiltration and continuous venovenous haemofiltration. Nephrology (Carlton) 2006;11:386-93.

9. Cole L, Bellomo R, Journois D, et al. High-volume haemofiltration in human septic shock. Intensive Care Med 2001;27:978-86.

10. Chung KK, Coates EC, Smith DJ, Jr., et al. High-volume hemofiltration in adult burn patients with septic shock and acute kidney injury: a multicenter randomized controlled trial. Crit Care 2017;21:289.

11. Lehner GF, Wiedermann CJ, Joannidis M, . Highvolume hemofiltration in critically ill patients: a systematic review and meta-analysis. Minerva Anestesiologica 2014;80:595-609.

12. Levy MM, Fink MP, Marshall JC, et al. [2.0] 2001 SCCM/ ESICM/ACCP/ATS/SIS International Sepsis Definitions Conference. Crit Care Med 2003;31:1250-6.

13. Lins RL, Elseviers MM, Van der Niepen P, et al. Intermittent versus continuous renal replacement therapy for acute kidney injury patients admitted to the intensive care unit: results of a randomized clinical trial. Nephrol Dial Transplant 2009;24:512-8.

14. Goldstein SL, Somers MJ, Baum MA, et al. Pediatric patients with multi-organ dysfunction syndrome receiving continuous renal replacement therapy. Kidney Int 2005;67:653-8.

15. Payen D, Mateo J, Cavaillon JM, et al. Impact of continuous venovenous hemofiltration on organ failure during the early phase of severe sepsis: a randomized controlled trial. Crit Care Med 2009;37:803-10.

16. Ronco C, Ricci Z, Bellomo R. Importance of increased ultrafiltration volume and impact on mortality: sepsis and cytokine story and the role of continuous venovenous haemofiltration. Curr Opin Nephrol Hypertens 2001;10:755-61.

17. Parikh CR, Belcher J. ACP Journal Club. Higher-intensity continuous renal-replacement therapy did not reduce mortality in critically ill patients with kidney injury. Ann Intern Med 2010;152:JC-25.

18. Bouman CS, Oudemans-van Straaten HM, Schultz MJ, et al. Hemofiltration in sepsis and systemic inflammatory response syndrome: the role of dosing and timing. J Crit Care 2007;22:1-12.

19. Heering P, Grabensee B, Brause M. Cytokine removal in septic patients with continuous venovenous hemofiltration. Kidney Blood Press Res 2003;26:128-34.

20. Morgera S, Haase M, Rocktaschel J, et al. High permeability haemofiltration improves peripheral blood mononuclear cell proliferation in septic patients with acute renal failure. Nephrol Dial Transplant 2003;18:2570-6.

21. Foland JA, Fortenberry JD, Warshaw BL, et al. Fluid overload before continuous hemofiltration and survival in critically ill children: a retrospective analysis. Crit Care Med 2004;32:1771-6.

22. Levy B, Sadoune LO, Gelot AM, et al. Evolution of lactate/pyruvate and arterial ketone body ratios in the early course of catecholamine-treated septic shock. Crit Care Med 2000;28:114-9.

23. Mikkelsen ME, Miltiades AN, Gaieski DF, et al. Serum lactate is associated with mortality in severe sepsis independent of organ failure and shock. Crit Care Med 2009;37:1670-7.

Cite this article as: Ning B, Ye S, Lyu Y, Yin F, Chen Z. Effect of high-volume hemofiltration on children with sepsis. Transl Pediatr 2020;9(2):101-107. doi: 10.21037/tp.2020.03.13 